\title{
Slovensko fôkselj (m.), gen. -na in sorodne besede
}

\author{
Helena Jazbec
}

Ker je v nemščini izpričano Faxe (f.) 'šala', Faxer (m.), gen. -s 'cirkuški klovn', v švabski nemščini faxen 'uganjati norčije', v koroški nemščini pa fàx (m.), gen. -es 'šaljivec', se ugotavlja, da so slovenske besede fôkselj, fóksne, fôksler, fôksner izposojene iz bavarske nemščine. Ustreznih predlog za vse omenjene izposojenke $v$ nemščini ni bilo mogoče najti, zato se izposoja dokazuje z nemškim besedotvorjem in s priponsko enakimi izposojenkami v slovenščini, ki imajo ustrezne nemške predloge.

ABSTRACT: Fôkselj, fôksner, fôksler and fóksne are Bavarian German loanwords in Slovenian. The original forms of these loanwords could not be found. The German nouns die Faxe(n) 'a joke', der Faxer 'a circus clown', der Fax 'a joker' and the verb faxen 'to joke' are the closest relatives to the etyma that could not be found. In order to prove the German origin of these words the German word-formation principles were analyzed and similar examples of German loanwords in Slovenian were studied.

\section{Sln. gradivo kot izhodišče za analizo*}

Besede fôkselj' (m.), gen. -na 'šaljivec, burkež; šala, norčija, burka' ne najdemo ne v Slovarju slovenskega knjižnega jezika (SSKJ) ne v Besedišču slovenskega jezika (Šircelj-Žnidaršič, 1998). Zapisana pa je bila v listkovnem gradivu za SSKJ: »Takšna irealno spredena žabja preproga je tudi vsa resničnost, ki straši in fokslne poka okrog naju« (Kermauner 1977: 29). Vsi ostali viri v tem listkovnem gradivu so neknjižni in so jih zapisali sodelavci Inštituta za slovenski jezik Frana Ramovša. Kolikor je bilo mogoče, sem vse te zapise ponovno preverila in k obrav-

* Za pomoč pri zbiranju gradiva se najlepše zahvaljujem Poloni Kostanjevec, Mariji Dolenc, Zvonki Leder - Mancini, Nataši Dobrila, Domnu Smole, dr. Janezu Dularju, prof. dr. Varji Cvetko - Orešnik, izr. prof. dr. Veri Smole, Carmen Kenda - Jež, izr. prof. dr. Majdi Merše, prof. dr. Viktorju Majdiču, Mariji Janežič, Mileni Hajnšek - Holz, Joži Meze in Janezu Kebru.

1 Gradivo navajam $z$ jakostnim naglasom, čeprav so bili informatorji tudi s tonemskega področja. 
navi pritegnila tudi nove primere, ki so mi jih posredovali delavci Inštituta za slovenski jezik Frana Ramovša, pa tudi informatorji od drugod.

1.1 Prof. dr. Viktor Majdič je v gradivu za SSKJ zapisal besedo fôkselj in jo umestil na mejno območje med savinjskimi in osrednještajerskimi narečji. Kot značilno besedno zvezo je navedel fôkseljne pokati 'šaliti se (v smislu situacijske komike)'. Marija Janežič je besedo fôkselj umestila na področje Ljubljane. Pozna jo v pomenu 'grimasa, kretnja, ki zabava' v zvezi fôkseljne uganjati ali zganjati. Zveza fôkseljne zganjati 'zbijati šale, biti šaljiv z besedami, mimiko, govorico telesa' je znana tudi Nataši Dobrila, katere govorica vključuje elemente notranjščine ter vzhodne kraščine. Besedo fôkselj 'burka, šala' v zvezi fôkseljne zbijati pozna s področja Ljubljane tudi prof. dr. Varja Cvetko - Orešnik.

Zvonka Leder - Mancini iz Ljubljane pozna fôkselj 'kdor izrabi vsako situacijo za komično domislico, šalo in zabava navzoče' npr. v zvezah Miha je pravi fokselj; Temu fokseljnu nikoli ne zmanjka.

1.2 Milena Hajnšek - Holz pozna z osrednje Štajerske besedo fóksne (f. pl.), gen. fóksen 'šale' v zvezi fóksne pokati ‘šaliti se'.

1.3 Dr. Janezu Dularju je iz Vavte vasi znana beseda fôkslar (m.), gen. -ja 'človek, ki razveseljuje družbo in je zato v njej zaželen; priložnostni zabavljač'. V gradivu za SSKJ najdemo tudi besedo fôksler (m.), gen. -ja 'tisti, ki zbija šale', ki jo je zapisala Joža Meze iz Ljubljane.

1.4 Janez Keber pozna z vzhodne Dolenjske besedo fóksnar (m.), gen. -ja 'šaljivec'. Izr. prof. dr. Vera Smole in Carmen Kenda - Jež poznata obliko fôksnar 'šaljivec' iz Šentruperta oziroma Dolenjskih Toplic. Izr. prof. dr. Majdi Merše je iz Vodic pri Ljubljani znano fôksner (m.), gen. -ja 'šaljivec', Mileni Hajnšek - Holz pa iz osrednje Štajerske fóksner 'šaljivec'.

Poizvedovanje je pokazalo, da se posamezni členi besedne družine fôkselj ‘šala, šaljivec', fóksne 'šale', fôksler 'šaljivec', fôksner 'isto', fôkslar, fôksnar govorijo na Dolenjskem, Štajerskem, na Krasu in v Ljubljani z okolico.

\section{Nem. gradivo kot izhodišče za analizo}

Vse zgoraj prikazane slovenske pogovorne besede so prevzete iz nemščine, saj je v nemščini izpričana besedna družina, v katero spada Faxe (f.) 'šala', ${ }^{2}$ ki se

2 Nekateri viri pišejo tudi Fachse-Grimm (1991: III, 1225) in Schmeller (1985: 1/1, 686) - kar je v nemščini bolj pogosto kot zapisovanje istega soglasniškega sklopa $[k s] \mathrm{z}-x$-. V nemških slovarjih je beseda predstavljena $\mathrm{z}$ naslednjimi pomenskimi odtenki: »1. possenhafte, spaßige Grimassen, Bewegungen, die belustigen sollen; 2. dumme, einsinnige Späße, alberne Ideen; dummes Zeug, Unsinn« (Drosdowski (1993: 1048); »1. Grimasse, Verzehrung des Gesichts, possenhafte Bewegung, die belustigen soll; 2. Unsinn, dummer, alberner, unsinniger Spaß; 3. Ausflüchte, Umstände« (Wahrig 1981: 683); »Possen, Albernheiten; Umstände; Ausflüchte« (Küpper 1983: 822); »sich zieren, Schwierigkeiten, Umstände machen « za Faxen machen (Benedikt 1979: 170); »Narrheiten, Umschweife« (Wehle 1980: 119); »1. Grimasse; 2. Possen, Scherze, Narrheiten, dumme Spässe, in Worten und Geberden; 3. Mach' mir keine Faxen = Arbeite mir nicht entgegen! « Fischer 
običajno pogovorno uporablja v množini die Faxen in pogosto v zvezi z glagolom machen: Faxen machen. $\mathrm{V}$ to besedno družino spadajo tudi Faxer (m.), gen. - $s$ 'cirkuški klovn' (Küpper 1983: 822), koroško nemško fàx (m.), gen. -es 'šaljivec' (Lexer, 1862: 87) ter švabsko nemški glagol faxen 'uganjati norčije' (Fischer 1908: 994). V nemščini je ta besedna družina mlada, saj je beseda Faxe izpričana šele v 17. stoletju (Kluge 1999: 253). ${ }^{3}$ Tudi zato so izposojenke fôkselj, fóksne, fôksler, fôksner, fôkslar, fôksnar mlade. Posrednik med nemščino in slovenščino je $\mathrm{v}$ teh primerih gotovo bavarska nemščina kot geografsko omejeni del visoke nemščine, v kateri se je nemški $a$ od začetka 13. stoletja dalje labiliziral v $o$. Nemški $a$ je v mnogih izposojenkah v slovenščino torej samo navidezno "zamenjan" s sln. $o$ : montel $\leftarrow$ nem. Mantel, popir $\leftarrow$ nem. Papier, saj so bile take izposojenke v slovenščino prevzete iz bavarskih fonetičnih predlog: mont l, popiar (Striedter - Temps 1963: 2). Čeprav ustreznih nemških predlog za fôkselj, fóksne, fôksler, fôksner, fôkslar, fôksnar ni, je prav ta "navidezna" substitucijska fonetika nemškega a s slovenskim $o$ znak, da je bila ta slovenska besedna družina izposojena iz bavarske nemščine in da je vsaj bavarska nemščina imela besedotvorne in oblikotvorne variante *Fochsel, *Fochsen, *Fochsler in *Fochsner.

\section{Pomenska dvojnost sln. fôkselj}

Sln. fôkselj pretežno pomeni 'šala', vendar tudi 'šaljivec'. Ker nem. Faxe pomeni samo 'šala', ne pa tudi 'šaljivec', se postavljata vprašanji, od kod sufiks -elj $\mathrm{v}$ besedi fôkselj, če ga nemško gradivo ne izpričuje, in od kod pomenska dvojnost sln. fôkselj, če je nemško gradivo tudi ne izpričuje. Poleg tega razvoj slovničnega pomena rezultata dejanja v vršilca dejanja v okviru iste besede, kot ga imamo v sln. fôkselj, ni potrjen. Pomeni, ki jih izpričujeta sln. fôkselj in nem. Faxe, pa tudi niso taki, da bi besedi lahko označili kot imeni dejanja. Iz imena dejanja se namreč ime vršilca dejanja lahko razvije, npr. sln. knjižno samomor 'dejanje, s katerim kdo namerno povzroči svojo smrt' in narečno 'samomorilec' (Pleteršnik 1894-1895: II, 454). Prav zato se zdi verjetno, da sta fôkselj 'šala' in fôkselj 'šaljivec' dve različni besedi, ki sta bili prevzeti iz bavarsko nemških homonimnih predlog. Ti pa sta nastali po dveh različnih besedotvornih vzorcih, in sicer po izsamostalniški in po izglagolski izpeljavi.

\subsection{SIn. fôkselj 'šala'}

Čeprav bi bilo možno predpostaviti, da je sln. fôkselj ‘šala’ domača izpeljanka iz sicer neizpričane prevzete besede *fôksa 'šala' po vzorcu možic $\rightarrow$ možicelj, je bolj verjetno, da je bilo sln. fôkselj v celoti prevzeto iz bavarsko nemške labializira-

(1908: 994); »kurzweilige Possen« (Adelung 1808: 63); »spaßhafte Einfälle; Possen« (Schmeller 1985: 1/1, 686); »Possen, Spässe, Einfälle« (Grimm 1991: III, 1225); »Spass, Scherz in Worten, Handlungen oder Geberden; Posse (bair.) (Lexer 1862: 87).

3 Etimologija nemške besede Faxe ni jasna. Kluge jo povezuje s Fickfack (m.), gen. -(e)s »izgovor, izmikanje, trik« (Kluge 1999: 253), Pfeifer pa s fatzen »norčevati se iz nekoga« (Pfeifer 1989: 416-417). 
ne predloge nemškega *Fachsel 'šala'. Obstoj take nemške oblike namreč potrjuje madž. množinska oblika faxlik 'Faxen', ki jo Benkő tako kot madž. sinonim fakszni izvaja iz nem. Faxe, Faxen, pri alternaciji -ni -li pa meni, da je *faxli (sg.) iz fakszni nastalo po analogiji s cetli 'listek papirja' iz nem. Zettel (Benkő 1992: 352, $157,164)$. Ker se 'alternacija' $-n-\sim-l$ - pojavlja tako v slovenskih kot v madžarskih prevzetih besedah, je bolj verjetno, da je bilo madž. *faxli - tako kot bicikli 'dvokolo' iz nem. bizykel 'isto' (Benkő 1992: 104), cetli 'listek papirja' iz nem. Zettel (m.), gen. $-s$ 'isto' (Benkő 1992: 164) in vurstli 'zabaviščni park' iz nem. Wurstel(prater) (m.), gen. -s 'zabaviščni park v dunajskem Pratru' (Benkő 1992: 1654) - prevzeto iz nem. *Fachsel 'šala'. Madž. faxlik torej kaže na obstoj nem. *Fachsel, sln. fôkselj pa na obstoj bavnem. labializirane predloge te nemške besede.

\subsubsection{Nem. Faxe 'šala' in *Fachsel 'isto'}

Slovenščina in madžarščina kažeta, da je v nemščini verjetno obstajala beseda *Fachsel in da je sodeč po slovenskih in madžarskih izposojenkah pomenila 'šala'. Ker je rekonstruirano *Fachsel 'šala' gotovo v besedotvornem razmerju z nem. Faxe (f.) 'šala', se postavlja vprašanje, v kakšnem besedotvornem razmerju sta ti dve nemški besedi in zakaj imata kljub besedotvornemu razmerju Faxe : *Fachs-el enak pomen.

Ker ima nem. sufiks -el zelo pogosto manjšalni pomen, ki se lahko tudi degramatikalizira, tako da se prvotna pomenska razlika v besedotvornem paru izgubi, se v nem. paru Faxe 'šala' : *Fachsel 'isto' verjetno kaže prav to besedotvorno razmerje. Podobno razmerje najdemo med nem. Krume (f.) 'drobtina' in Krümel (m.) 'isto', med nem. Bund (n.) ‘šop, sveženj' in Bündel (n.) 'isto', prvotno razmerje nevtralna beseda : deminutiv pa se lepo ohranja npr. med $R o \beta$ (n.) 'konj' in Rössel (n.) 'konjiček' (Erben 1993: 83-84).

Tudi večina drugih izposojenk $\mathrm{z}$ nemškim deminutivnim sufiksom - $e l \mathrm{v}$ slovenščini nima pomena manjšalnice, vendar je pogosto težko ugotoviti, ali se je deminutivni pomen izgubil že na nemški ali šele na slovenski strani.

Tako je npr. sln. tôšelj (m.), gen. -na 'denarnica' (Domen Smole, ustno, Tacen) zaradi -o- iz bavarsko nemške predloge *(Geld-)toschel 'denarnica', deminutivne tvorbe k nem. Geldtasche 'isto', ki se ohranja v kornem. tásch.l 'torbica' (Lexer 1862: 52). Podobni primeri so še npr. gartelj, -na 'vrt' iz bavavstr. narečnega gart.l 'vrtiček' (Striedter - Temps 1963: 127), krágelj, -na 'ovratnik' iz bavavstr. narečnega kragel 'ovratniček' (Striedter - Temps 1963: 156), ládelj, -na 'predal' iz bavavstr. narečnega lâd·l 'predalček' (Striedter - Temps 1963: 164), žákelj, -klja 'vreča' iz bavavstr. narečnega sack $\cdot l$ 'vrečka' (Striedter - Temps 1963: 248).

\subsection{Sln. fôkselj 'šaljivec'}

V nemščini obstajajo deverbativni vršilci dejanja na -el, npr. nvn. Büttel 'birič', stvn. butil 'isto' iz glagola stvn. biotan (> nvn. bieten) 'ponujati'. Danes so redki, ker so jih izpodrinili vršilci dejanja na -er, npr. stvn. tregil 'nosilec', toda nvn. Träger 'isto', stvn. tribil 'gonjač', toda nvn. Treiber 'isto', srvn. kempel 'borec', toda nvn. Kämpfer 'isto' (Fleischer-Barz 1995: 150-151). Med starejše tovrstne vršilce dejanja spada tudi (Feld)webel 'narednik', srvn. weibel 'sodni kurir', stvn. weibil 'isto', ki je izpeljan iz stvn. weibōn 'premikati se sem in tja' (Drosdow- 
ski 1989: 495; Kluge 1999: 257, 880) in izposojen v sln.feldvébel 'narednik' (Striedter - Temps 1963: 116).

Tudi nem. Trottel (m.) 'bedak', ki se je v prvi polovici 19. stoletja v bavarski avstrijščini uporabljal v pomenu 'kreten (medicinsko)' in je kot trótelj (m.), gen. -na 'omejen, neumen človek' (SSKJ 1991: V., 191) izposojen v slovenščino, je verjetno vršilec dejanja na -el iz glagola trotten 'neokretno, štorasto, nerodno, lahko tudi zibajoč se, opotekajoč se hoditi' (Grimm 1991: XXII, 1076-77). Za kretenizem je namreč hoja, ki jo izraža ta glagol, značilna. Glagol trotteln 'počasi in neokretno, štorasto, nerodno hoditi' je zaradi pomena bolj verjetno izglagolski deminutiv iz trotten tipa hüsteln 'pokašljevati' iz husten 'kašljati' (Krahe-Meid 1967: III, 263), kot pa denominativ iz Trottel 'bedak, kreten'.

\section{Sln. fóksne (f. pl.) 'šale'}

Beseda fóksne (f. pl.) 'šale' je bila prevzeta iz bavnem. labializirane predloge *Fochsen za nem. Faxen, množine k Faxe (f.) ‘šala’. Nemški ženski spol se v slovenščini lepo ohranja, prim. gen. pl. fóksen. V pluralni obliki je bilo nem. Faxe ‘šala' prevzeto tudi v gemersko slovaško narečje kot faksne (f. pl.), gen. -i 'nesmisli, neumnosti, bedarije' (Orlovský 1982: 79), v pogovorno hrvaščino kot fàksni (m. pl.), gen. fáksnā 'norčije' in fàksne ali fáksnī (f. pl.), gen. fáksna 'isto' (Jurančič 1986: 234) in kot je bilo že omenjeno, v madžarščino kot fakszni 'šala' (Benkö 1992: 352).

Oblikotvorno enaka izposojenka je sln. narečno zókne (f. pl.), gen. zóken 'nogavice' (Domen Smole, ustno, Tacen), v popisu slovenskega besedišča pa najdemo tudi edninsko obliko zóken (m.), gen. -kna. ${ }^{4}$ Množinski samostalnik zókne (f. pl.) je bil prevzet iz nvn. množinske oblike Socken k Socke (f.) 'kratka nogavica'.

\section{Sln. fôksnar/-er 'šaljivec' in fôksler/-ar 'isto'}

V koroški nemščini je znan vršilec dejanja fàx (m.), gen. -es 'šaljivec' (Lexer, 1862: 87), v pogovorni nemščini pa Faxer (m.), gen. -s 'cirkuški klovn' (Küpper 1983: 822). Nemških besedotvornih variant vršilcev dejanja, na katere kažejo sln. fôksnar/-er 'šaljivec' in fôksler/-ar 'isto', mi ni uspelo najti.

Nemška imena vršilca dejanja se najpogosteje tvorijo z -er, -ler ali -ner: Fahr-er 'voznik', Liebhab-er 'ljubimec', Nachfolg-er 'naslednik'; Tisch-ler 'mi-

4 V listkovnem gradivu za SSKJ je naveden vir: »Dokler ne bomo imeli prikladnih domačih izrazov, bodo naši ljudje pač uporabljali tujke in spačenke, to velja tako za stare kakor za nove besede. Dokler nimamo primerne besede za kratke nogavice, bodo ljudje pač govorili 'zokni', ipd.« (Gradišnik 1967: 47). Oblika zóken (m. sg.), gen. -kna, pl. zókni (naglas po Šircelj - Žnidaršič 1998: 983) je lahko izposojena iz nvn. predloge Socken (m. sg.), gen. -s, ki je sinonimna z nvn. Socke (f. sg.) 'kratka nogavica', govori pa se le v južni Nemčiji, Avstriji in Švici (Drosdowski 1989: 1412). 
Adelung, J. C., 1808, Grammatisch-kritisches Wörterbuch der hochdeutschen Mundart, Wien.

Bajec, A., 1950, Besedotvorje slovenskega jezika I, Izpeljava samostalnikov, Ljubljana.

Benedikt, E., Hornung, M., Pacolt, E., 1979, Österreichisches Wörterbuch, Wien. Benkő, L., 1992, Etymologisches Wörterbuch des Ungarischen, Budimpešta.

Bezlaj, F., 1964, Nemške izposojenke v slovenščini, Dopisnik III/ 10, 5.

Debenjak, D., 1993, Veliki nemško-slovenski slovar, Ljubljana.

5 Nemški sufiks -er se je fonetično razvil iz stvn -āri (ta pa je iz latinskega -ārius): stvn. zol(l)anāri $>$ nvn. Zöllner, stvn. learāri > nvn. Lehrer, stvn. iagāri > nvn. Jäger (Bajec 1950: 25; Erben 1993: 136-137). Besede, ki so bile iz nemščine v slovenščino prevzete še v času stare visoke nemščine, so prevzele različico na -ar. Torej so jih naši predniki prevzemali, preden se je $-\bar{a}-$ v stvn. $-\bar{a} r(i)$ začel razvijati v smeri proti prednjemu samoglasniku. Tuje obrazilo -ār(i) so sprejeli hkrati s tujo besedo (hlevar), toda kmalu ga je začel jezik pripenjati na domače korene (drvar, glavar, klobučar, rudar, vratar, zobar). 
Drews, G., 1991, Das Bayerische Schimpfwörterbuch, Nidderau.

Drosdowski, G., 1993, Duden, Das große Wörterbuch der deutschen Sprache in 8 Bänden (2., völlig neu bearbeitete Auflage), Mannheim-Leipzig-WienZürich.

Drosdowski, G., 1989, Duden, Deutsches Universalwörterbuch (2., völlig neu bearbeitete und stark erweiterte Auflage), Mannheim-Leipzig-Wien-Zürich.

Erben, J., 1993, Einführung in die deutsche Wortbildungslehre, 3., neubearbeitete Auflage, Berlin.

Fischer, H., 1908, Schwäbisches Wörterbuch, Tübingen.

Fleischer, W., Barz, I., 1995, Wortbildung der deutschen Gegenwartssprache, Tübingen.

Gradišnik, J., 1967, Slovenščina za Slovence, Maribor.

Grimm, J. und W., 1991, Deutsches Wörterbuch I-XXXIII, Nachdruck der Erstausgabe 1854-1984, München.

Jurančič, J., 1986, Srbskohrvatsko-slovenski slovar, tretja, znatno razširjena izdaja, Ljubljana.

Kermauner, T., Družbena razveza, Problemi - Literatura XV (1977), št. 8, 29-37.

Kluge, F., 1999, Etymologisches Wörterbuch der deutschen Sprache. 23., erweiterte Auflage, bearbeitet von Elmar Seebold, Berlin.

Krahe, H., Meid, W., 1967, Germanische Sprachwissenschaft. III. Wortbildungslehre, Berlin.

Küpper, H., 1983, Illustriertes Lexikon der deutschen Umgangssprache, Stuttgart.

Lexer, M., 1862, Kärntisches Wörterbuch, Leipzig.

Orlovský, J., 1982, Gemerský nárečový slovnik, Rimavská Sobota.

Pfeifer, W., 1989, Etymologisches Wörterbuch des Deutschen, Berlin.

Pleteršnik, M., 1894-1895, Slovensko-nemški slovar I-II, Ljubljana.

Ramovš, F., 1924, Historična gramatika slovenskega jezika II. Konsonantizem. Ljubljana.

Schmeller, J. A., 1985, Bayerisches Wörterbuch, Sonderausgabe der von G. Karl Frommann bearbeiteten 2. Ausgabe, München 1872-1877, München.

Slovar slovenskega knjižnega jezika I-V, 1970-1991, Ljubljana.

Stepanowa, M. D., Fleischer, W., 1985, Grundzüge der deutschen Wortbildung, Leipzig.

Striedter - Temps, H., 1963, Deutsche Lehnwörter im Slowenischen, Berlin.

Šircelj - Žnidaršič, I., 1998, Besedišče slovenskega jezika z oblikoslovnimi podatki, Ljubljana.

Wahrig, G., Krämer, H., Zimmermann, H., 1981, Brockhaus Wahrig-Deutsches Wörterbuch in 6 Bänden, Wiesbaden.

Wehle, P., 1980, Sprechen Sie Wienerisch?, Wien - Heidelberg.

\section{Seznam okrajšav}

bavavstr. = bavarsko avstrijsko

bavnem. = bavarsko nemško

f. $=$ femininum (ženski spol)

gen. = genitiv (rodilnik) 
kornem. $=$ koroško nemško

m. = masculinum (moški spol)

n. = neutrum (srednji spol)

nem. $=$ nemško

nvn. = novovisokonemško

pl. = plural (množina)

\% prim. $=$ primerjaj

sg. = singular (ednina)

- $\quad \sin .=$ slovensko

srvn. = srednjevisokonemško

$z \quad$ str. $=$ stran

stvn. = starovisokonemško

\section{Slowenisch fôkselj (m.), Gen. -na und verwandte Wörter (Zusammenfassung)}

(n) Fôkselj, fôksner, fôksler und fóksne sind bayerisch-deutsche Lehnwörter im

Slowenischen. Die echten Vorlagen dieser Lehnwörter im Deutschen wurden leider

nicht gefunden. Die deutschen Substantiven die Faxe(n), der Faxer, der Fax und das Verb faxen sind den nicht gefundenen Etyma am nächsten verwandt. Um diese zwei Wortfamilien, nämlich die slowenische und die deutsche, in eine Entlehnungsbeziehung zu bringen, wurden die vorhandenen deutschen Wortbildungsmuster in Betracht gezogen. Dazu kommen ähnliche Entlehnungsbeispiele aus dem Deutschen ins Slowenische. 